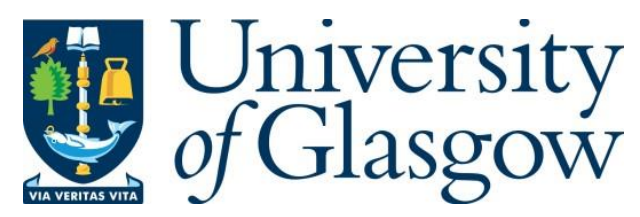

Curl, A. and Mason, P. (2019) Neighbourhood perceptions and older adults' wellbeing: does walking explain the relationship in deprived urban communities? Transportation Research Part A: Policy and Practice, 123, pp. 119-129.

There may be differences between this version and the published version. You are advised to consult the publisher's version if you wish to cite from it.

http://eprints.gla.ac.uk/193188/

Deposited on: 15 August 2019

Enlighten - Research publications by members of the University of Glasgow http://eprints.gla.ac.uk 


\title{
Neighbourhood perceptions and older adults' wellbeing: does walking explain the relationship in deprived urban communities?
}

\begin{abstract}
There is increased awareness of the role of the urban landscape in promoting walking to counter the negative health and wellbeing impacts of age-related immobility. Consideration of neighbourhood design is particularly relevant in the context of local urban regeneration projects, which are designed to have positive health and wellbeing outcomes. However, most studies do not explicitly set out to understand how the environment influences walking and wellbeing for older adults living in a deprived urban area.
\end{abstract}

There are strong conceptual and empirical links between walking, environment and mental wellbeing. Many studies have separately demonstrated pairwise associations between all three components.. In this paper we address these three concepts empirically, using structural equation modelling to explore walking as a mediator between the perceived social and built environments and mental wellbeing for older adults in deprived urban areas.

We found direct and indirect relationships between neighbourhood perceptions and wellbeing. Walking partially mediates relationships between social contact, neighbourhood quality, local amenity use, safety and mental wellbeing. Although neighbourhood problems and the quality of local services and amenities are associated with mental wellbeing, walking is not an explanatory pathway in our model. The relationship between walking and wellbeing is weaker than expected.

While promoting walking as a means of achieving positive mental wellbeing among older adults is important for "active ageing", it is also necessary to consider the context in which this takes place, recognising that walking is not the only causal pathway between environment and wellbeing. Where walking is relied upon for transport, the wellbeing implications may be more complex. Given the strong associations between car ownership and wellbeing, future research should explore whether mobility and accessibility, rather than walking itself, is more important for older adults' wellbeing. 
Keywords: deprived urban communities; mobility; wellbeing; neighbourhood environment; ageing 


\section{Introduction}

This paper simultaneously addresses environment, walking and mental wellbeing to further our understanding of how the three concepts are related for older adults living in deprived urban areas.

Active travel is receiving increasing policy attention as a mechanism to support healthy and sustainable urban development, but studies usually assume that walking will have positive health and wellbeing impacts. This assertion has been questioned (Bostock, 2001). For example, in the context of single mothers who relied on walking for transport, the stress and fatigue, alongside walking through unpleasant environments meant that walking had negative influences on wellbeing (Bostock, 2001). Therefore, while walking, as a mode of active travel has the potential to promote population health and wellbeing more attention needs to be paid to different populations groups and urban contexts in order to avoid perpetuating rather than addressing social exclusion and health inequalities for marginalised groups (Stafford and Baldwin, 2018).

Therefore, despite increasing attention being paid to the potential of the built environment to support wellbeing, partly because it can support active travel, it important to consider how the built environment supports walking and wellbeing for those who rely more heavily on walking as a mode of transport. Walking is a particularly important mode of transport for older adults and for those who live in deprived areas, yet one that has been relatively little studied. Older adults' ability to drive can deteriorate with age, and those on lower incomes may struggle to afford to travel by other modes. Although income and area level deprivation are not the same thing, those living in deprived urban areas are more likely to have difficulties affording transport and to rely on walking for their daily mobility (Ogilvie et. Al, 2008). For example, in the sample of older adults living in deprived areas considered in this study, only $22.4 \%$ of households owned a car, demonstrating the likely importance of walking for transport.

Ensuring that the mobility needs of those groups most likely to be considered vulnerable to transportrelated social exclusion is important from a transport justice perspective. Mobility and, consequently, transport systems can both promote or limit quality of life and wellbeing of populations. Individuals 
who do not have access to a car are more likely to walk, which can be health promoting, but in a cardependent society (Cahill, 2010)can be at risk of exclusion from accessing destinations important for health and wellbeing.

Nordbakke and Schwanen, (2013) conceptualise three ways in which mobility influences wellbeing. First, being mobile facilitates access to destinations and social connections that are important for health and wellbeing. Second, being mobile can have physical health benefits through the physical activity undertaken while moving. Finally, having the means to be mobile or to access important places can be important for feelings of wellbeing, even if that mobility does not actually occur.

In this paper, we examine how the urban environment may support walking as a means of transport and whether that influences wellbeing. Physical health benefits related to physical activity are often considered a pathway between well designed urban environments and wellbeing, although others, including those of social engagement, accessibility, and safety and security, may link the two (Burton, 2015). We consider the wellbeing benefits of walking to include, but not be limited to, those of physical activity.

The relationship between walking and wellbeing is particularly pertinent to older adults (Lampinen et al., 2006), given that older people may be less physically capable than the young and therefore tend to be less mobile (Schwanen and Páez, 2010).

From a health perspective, these relationships between the urban environment, walking (or physical activity) and health and wellbeing have been attracting an increasing degree of interest (Koohsari et al., 2013). In an urban context, considerable effort has been expended to determine the personal, residential, neighbourhood and community factors that influence the wellbeing of populations, and how the urban landscape can be better designed to sustain health and wellbeing (Dannenberg et al. 2012).Urban environments may influences health and wellbeing in a number of ways, but the potential of the design of places to influence active travel is increasingly recognised. Such a relationship assumes that the built environment influences health and wellbeing because of the behaviours (e.g walking) that it supports. 
In addition to its role as a mode of transport, walking is a common form of physical activity, especially for older adults (Bergland et al., 2010). Given its potential physical health and mental wellbeing benefits, it is increasingly promoted as part of "active ageing" agendas. Active older adults have a lower risk of falls, cardiovascular disease and obesity-related conditions.

The neighbourhood environment can improve positive mental wellbeing by enabling walking (Sugiyama and Ward Thompson, 2007a) but few studies that have examined this pathway have addressed walking and health separately, but rather, have assumed positive associations between walking and health.

Although relationships between environment and wellbeing are usually indirect (Burton, 2015), few studies have explored these causal pathways. Many studies have focused on the pairwise relationships between environment, mobility and wellbeing, but all three aspects have seldom been addressed simultaneously, especially in the context of older people. Given older adults tend to experience decline in personal physical capabilities, the neighbourhood environment is particularly likely to influence the mental wellbeing of older people since they are more likely to spend more time in the local environment (Gale et al., 2011).

Our research project has previously examined the relationships between physical activity and wellbeing [reference removed for peer review], neighbourhood environment and walking behaviour [reference removed for peer review] and the neighbourhood environment and wellbeing [reference removed for peer review] in adults of all ages. Other studies have explored the relationship between the physical and social environment and walking (Franke et al., 2013; McCormack et al., 2014; Ogilvie et al., 2008; Van Cauwenberg et al., 2011) and between walking and mental wellbeing (Cerin et al., 2009). Ogilvie et al. (2008) studied the same deprived urban context as featured in this study, and we extend that study by examining wellbeing outcomes from the environment and walking.

Sugiyama and Ward Thompson (2007b) found independent relationships between perceived environmental support and walking, and environmental support and physical and mental health, suggesting that the environment is important for wellbeing, both directly and, through facilitation of 
walking, indirectly. Shortt et al. (2014) conceptualise walking (as physical activity) as the pathway between the environment and physical health inequalities, although they assume a relationship between physical activity and health, which may not be the case for non-recreational walking (Christiansen et al., 2014; Ogilvie et al., 2008; Shortt et al., 2014). Assumed relationships between walking and health might be particularly problematic in the deprived urban context in which our study takes place, given that walking for transport is usually more common among more deprived populations, although health outcomes are usually poorer.

Many of the environmental and social factors associated with wellbeing are similar to those associated with walking. There is therefore a need to unpick the relationships between these factors and wellbeing to determine whether associations between the urban environment and wellbeing can be explained by, or are independent of, walking. We explore the relationship between the environment, walking and mental wellbeing in a sample of adults aged 60 years or more.

Structural equation modelling is an ideal approach for exploring walking as a mediator of relationships between the built and social environment and the mental wellbeing of older people. We do this in the context of 15 deprived communities in Glasgow, UK, that are undergoing a range of residential and neighbourhood regeneration activities.

Our conceptual framework is shown in Figure 1. We conceptualise that there can be direct links and, via walking, indirect links between the built and social environments and wellbeing.

\section{[Figure 1]}

\subsection{Research aims}

This paper aims to explore walking as a mediator of the relationship between perceptions of the environment and mental wellbeing for older adults in deprived urban communities. To this end, we address the following research questions:

- How is the frequency of walking among older adults related to mental wellbeing? 
- Which social and built environment factors are important for older adults' (a) wellbeing and (b) walking in deprived urban communities?

- Does the frequency of walking among older adults mediate between the social and built environment and wellbeing in a deprived urban context?

\section{Material and Methods}

\subsection{Study context}

Our study was conducted in Glasgow as part of the [study name removed for peer review], an ongoing investigation into the consequences of major residential, neighbourhood and community regeneration programmes. This study examines cross-sectional data from the third wave of a survey of residents, conducted in 2011.

4,269 Glasgow residents were interviewed in their homes in the spring or summer of 2011.95 per cent of these people were living in one of 15 specific deprived neighbourhoods, the remainder living elsewhere in the city, having moved from one of the study areas at some time during the previous 5 years. The overall response rate was 45.4 per cent. For the analyses presented here, we selected respondents who were British citizens, aged 60 years or more. Only those with complete data for the variables examined were included in the final analytical sample of 1,071 respondents.

The questionnaire sought information about respondents' personal and residential circumstances, their physical and mental health, their recent physical activity and their opinions and experiences of their homes, neighbourhoods and communities.

Ethical approval was given by the NHS Scotland B MREC committee (no. 05/MRE10/89).

\subsection{Analytical approach}

For the descriptive analysis, variables of interest are summarised as percentages (categorical variable classes) and means and standard deviations (continuous variables). 
We use structural equation modelling to explore the simultaneous direct and indirect relationships between neighbourhood perceptions and mental wellbeing with walking as a mediator (Figure 2). We use a diagonally weighted least squares estimator (WLSMV), which accounts for the ordinal nature of the walking frequency variable. It uses diagonally weighted least squares (DWLS) to estimate the model parameters and the full-weight matrix to compute robust standard errors (Rosseel, 2012).

We used SPSS v.22.0 (IBM Corp., Armonk, NY) for the descriptive analyses and the lavaan (v0.5-18) package in $\mathrm{R}(\mathrm{v}$ 3.0.2) for structural equation modelling.

\subsection{Sample composition}

The composition of the sample is summarised in Table 1. A high proportion (almost 60 per cent) of the sample was female, close to the proportion in the overall population of these areas (58.3\%). Almost half of the respondents (47 per cent) were in the youngest age group (60-69 years), whilst only around one in seven were aged 80 years or more. The majority ( 83 per cent) were retired, and 12.5 per cent claimed to be of working age but without a job (mainly men aged 60-64 years). Almost three in five of the respondents lived alone. Only approximately one in eight of the respondents had more than the most basic Scottish educational qualification (the School Leaving Certificate, SLC). Access to a car was uncommon (slightly more than a fifth of those interviewed). Slightly fewer than half of the respondents lived in a house, while just under a fifth lived in a flat in a high-rise block. Three-quarters of participants were social-renters.

Overall, 60.7 per cent of respondents reported at least one long-term physical condition. By far the most common ailments, reported by half of the participants, were of a cardiovascular or respiratory nature. Musculoskeletal and neurophysiological conditions were cited by a small minority ( 6.4 per cent) of respondents. Just over a fifth of people claimed to suffer from at least one other type of longterm physical health condition. It should be noted that there is no indication of the severity of any of these conditions.

Given our focus on a specific population group the sample cannot be considered representative. We cannot be sure how representative our sample is of the older populations in the study areas, since 
these neighbourhoods comprise non-standard geographies and because data are not readily available for the specific age-groups we consider here.

[Table 1]

\subsection{Mental wellbeing measure}

Mental wellbeing is measured using the Warwick-Edinburgh Mental Wellbeing Scale (WEMWBS) (Tennant et al., 2007). Scores are derived from five-point frequency-scale responses to 14 positively phrased statements about respondents' subjective happiness and effective psychological functioning over the previous two weeks. The scale has good psychometric properties (Stewart-Brown et al., 2009). Responses are usually summed to give scores between 14 (poorest mental wellbeing) and 70 (best mental wellbeing), but in this paper we conceptualise mental wellbeing as an endogenous latent variable with 14 measured indicator variables (see below). In confirmatory factor analysis, the latent wellbeing variable explained significant variation in each of the 14 components and the model fit was acceptable $(\mathrm{CFI}=0.921$; RMSEA=0.08), confirming the measure to be appropriate for the sample. We included error covariance between some items, as detailed in Table 2, to improve the model fit.

\section{[Table 2]}

\subsection{Walking measure}

Walking is an endogenous variable in our analysis as it is explained by other variables in the model. The frequency of neighbourhood walking was assessed from the question "In the last seven days, on how many days did you walk in your neighbourhood for at least 20 minutes at a time?", which elicits responses of 0 to 7 days (respondents who replied "don't know" or who refused to respond were excluded from the sample). The question aimed to address neighbourhood walking for the purposes of doing errands or as a leisure activity. While it is an arbitrary measure, 20 minutes was chosen for the wider survey because it is equivalent to a 10-minute return trip of around $800 \mathrm{~m}$ in an adult population, which is a threshold commonly used in such studies (Ogilvie et al., 2008) to distinguish 
those who walk in the local area from those who do not. We recognise the limitations here because our analytical sample is older than the general adult population, and so may walk more slowly, but we are limited by the data collected in the overall study.

\subsection{Measures of the social and built environment}

Many researchers have highlighted the importance of the neighbourhood (Yen, Michael, and Perdue 2009) and social environment for the health and mental wellbeing of older adults in particular. We used several variables to measure perceptions of the built and social environments. In the wider study, questions included in the survey were selected based on factors known to be important for community wellbeing and the interests of the various project funders. Variables included in this analysis were chosen because they had been related to walking and wellbeing in our previous research (references removed for peer review). Six of these are exogenous latent variables in the model and three are manifest variables, as outlined below.

\subsubsection{Neighbourhood quality}

We included four indicator variables in our latent measure of neighbourhood quality: attractive buildings; attractive environment; quiet and peaceful environment and parks and open spaces.

\subsubsection{Neighbourhood problems}

We considered two latent variables for neighbourhood problems: incivilities and environmental items. The indicator variables are shown in Table 3 .

\subsubsection{Quality and use of local amenities}

We used three measures to capture the quality and use of local services: first, a latent variable of the quality of local services that included policing, street cleaning, public transport street lighting and paths (Table 2), and two derived variables representing the use of one or more of four retail amenities (post office; small/local grocers; supermarket; retail or shopping centre) and of six non-retail 
amenities (sport facilities, swimming pool or gym; social venues; park or play area; library; community centre) in the past 7 days.

\subsubsection{Social contact}

We measured social contact using a latent variable based on three measures of frequency of contact: with family, friends and neighbours. We also included a manifest variable to indicate whether respondents lived with anyone as an indicator of social contact.

\subsubsection{Personal safety}

We measured perceptions of safety using a manifest variable: Feelings of safety walking in the dark ( $1=$ very unsafe/never walk alone after dark; $5=$ very safe), which is designed to capture perceptions of personal and crime-related safety in the neighbourhood.

\subsection{Sociodemographic, personal and residential characteristics and health}

We included car ownership and education (in the absence of an income measure and as a proxy for socio-economic status) as measured variables. Additionally, car use is likely to be related to walking in its own right as people who use a car typically walk less frequently for transport.

Respondents were asked whether they had suffered regularly from any of several health problems (skin conditions, allergies; breathing problems, asthma, bronchitis; heart, high blood pressure, circulatory problems; stomach, liver, kidney, digestive problems; migraine, frequent headaches; any other condition specified by respondent) during the previous twelve months. We reclassified these responses into three groups of long-term health conditions: cardiovascular or respiratory illness; musculoskeletal or neurophysiological illness likely to impede walking; any other physical health problem. Mental health conditions were not included in the analysis due to their strong negative association with mental wellbeing. 
We adjusted the model to account for sociodemographic, personal and residential characteristics including gender (male; female), age group (60-69; 70-80; 80+ years), household type (living alone; living with 1+ person), employment and education (none, up to SLC, or don’t know; above SLC).

\section{Results}

The results showing the relationship between each of the exogenous (predictor) variables and the two endogenous (outcome) variables, walking and mental wellbeing, are shown in Table 3 and Figure 3.

[Table 3]

[Figure 3]

The model fit indices $(\mathrm{CFI}=0.93$; RMSEA=0.04) were acceptable and close to the cut-off values of 0.95 (CFI) and 0.06 (RMSEA) suggested by Hu and Bentler (1999).

\subsection{Associations with mental wellbeing}

Social contact, perceived neighbourhood quality and environmental neighbourhood problems had the strongest direct, positive associations with wellbeing. Cardiovascular and respiratory health conditions had the strongest, direct negative association with wellbeing.

As expected, neighbourhood walking was positively associated with mental wellbeing, although the small coefficient, predicting an increase in WEMWBS score of only 0.04 for each extra day of neighbourhood walking, cannot be considered substantive. 
All of the neighbourhood perception variables except for perceived quality of local amenities were significantly associated with mental wellbeing. Neighbourhood quality $(\mathrm{B}=0.15)$ and the quality of local services $(B=0.17)$ were positively associated with mental wellbeing. The two neighbourhood problem variables had opposing associations with mental wellbeing: incivilities were negatively associated $(\mathrm{B}=-0.18)$, but, surprisingly, environmental problems were positively associated with wellbeing $(\mathrm{B}=0.27)$. Using retail $(\mathrm{B}=0.09)$ and non-retail $(\mathrm{B}=0.12)$ amenities was associated with better mental wellbeing, whereas no significant associations were found with the perceived quality of any amenities.

Social contact was positively associated with wellbeing $(B=0.25)$, as expected. Living alone was associated with a 0.07 lower WEMWBS score than for those who do not live alone. Cardiorespiratory health problems $(B=-0.19)$ and other physical health conditions $(B=-0.16)$ were associated with worse mental wellbeing, although this was not the case for musculoskeletal health problems.

Age was associated with higher mental wellbeing scores, whereby those aged 70-79 years and 80 years or older reported higher mental wellbeing scores than those in the youngest age group (60-69 years). Those who reported that they would feel safe walking alone in their neighbourhood after dark reported higher mental wellbeing scores than those who would not feel safe. Owning, or having regular access to a vehicle was also associated with higher mental wellbeing scores. Women reported higher mental wellbeing scores than men in our sample $(\mathrm{B}=0.14)$ and those with educational qualifications had higher wellbeing scores than those without $(B=0.12)$.

\subsection{Associations with walking}

Use of local retail and non-retail amenities, social contact and perceived neighbourhood quality were most strongly associated with walking more frequently in the local area. Car ownership was most strongly associated with a lower frequency of walking. Feeling safe walking in the dark was also associated with walking more frequently in the local neighbourhood $(B=0.07)$. Neighbourhood problems were not significantly associated with walking. Car ownership $(B=-0.47)$, cardiorespiratory $(\mathrm{B}=-0.18)$ and other physical health $(\mathrm{B}=-0.21)$ conditions, as well as increasing age (age 70-79 years, 
$\mathrm{B}=-0.15 ; 80+$ years, $\mathrm{B}=-0.35$ ) were associated with a lower frequency of walking. Finally, those with educational qualifications walked more frequently than those without $(B=0.301)$.

\subsection{Walking as a mediator}

Walking is included in our model as a mediating variable. It is endogenous because it is explained by other variables in the model, but it also explains another variable (wellbeing). The model structure means that because there is a significant, though weak, positive association between walking and wellbeing, any exogenous variables significantly associated with walking in the structural equation model can be interpreted as having an indirect effect on wellbeing, through walking, in addition to any direct effects they may have on wellbeing. Where there are both direct and indirect relationships between an exogenous variable and mental wellbeing, walking partially mediates the relationship of that variable with wellbeing. Therefore, if our social and built environment variables are both directly, and indirectly associated with wellbeing, walking partially explains why the variable is associated with wellbeing. If the relationships are only indirect, then that variable is only associated with wellbeing because it supports walking, which is itself a positive influence on wellbeing. For example, the conceptual diagram (Figure 1) indicates that the built environment may have direct influences on wellbeing, but also an indirect effect as a result of the built environment influencing walking, which itself influences wellbeing. This relationship between walking and wellbeing is confirmed in our model, so any significant relationships between predictor variables and walking are interpreted as being significant indirect relationships with wellbeing.

Walking can therefore be interpreted as a mediator of perceptions of neighbourhood quality and of social contact with positive mental wellbeing. Although these variables were independently associated with mental wellbeing, those who had positive perceptions of neighbourhood quality or higher levels of social contact and who also walked more frequently in the local area tended to have higher mental wellbeing scores. Similarly, walking was a significant mediator of the effect of the use of local amenities on mental wellbeing. 
Feeling safe walking in the dark was linked to better mental wellbeing not only directly, but also indirectly, through more frequent neighbourhood walking. Less frequent walking among those with cardiorespiratory $(\mathrm{B}=-0.2)$ and other physical health problems $(\mathrm{B}=-0.17)$ partially explained why those with physical health conditions tended to report worse mental wellbeing. Older age was negatively associated with walking and positively associated with wellbeing. The unstandardised total effects were positive (Age $80+$ years, $B=0.12$ ). Household vehicle ownership was associated negatively with walking but positively with mental wellbeing. The unstandardised total effects were positive $(\mathrm{B}=0.07)$. This suggests that, despite the negative effects of car ownership on walking behaviour, having access to a vehicle is still better overall for mental wellbeing in older households.

In summary, social contact, neighbourhood quality, use of local amenities, physical health conditions and feeling safe walking in the neighbourhood at night have significant effects on wellbeing, which can be partially explained by neighbourhood walking. Neighbourhood problems and the perceived quality of local amenities have significant effects on mental wellbeing that cannot be explained by walking. Age and car ownership are both negatively associated with the frequency of walking and have negative indirect effects, but given, stronger positive direct effects have positive overall effects on wellbeing.

\section{Discussion}

\subsection{Perceptions of the neighbourhood, walking and mental wellbeing: links}

Our findings reinforce the importance of social contact, neighbourhood quality, local amenities and perceptions of safety for neighbourhood walking and mental wellbeing in older populations and add to the existing body of knowledge by providing empirical support for the notion that walking partially explains the associations of these factors with mental wellbeing.

Neighbourhood incivilities had a direct negative relationship with mental wellbeing, but did not influence walking in our sample. This supports the idea that walking may be utilitarian rather than a positive choice in deprived communities, helping to explain the weak associations with wellbeing. It is difficult to explain why environmental neighbourhood problems such as vandalism, graffiti, litter, 
damaged properties and vacant land, poor air quality and traffic would be positively associated with mental wellbeing. This finding runs contrary to our expectation and to previous evidence that neighbourhood problems are negatively associated with wellbeing (Jones et al., 2014). If the positive relationships between neighbourhood problems and walking were stronger, one explanation might be that such neighbourhood problems are more visible to those who are outside more often and who also have higher mental wellbeing scores. For example, Mason et al. (2013) found positive associations between adults perceiving drug problems and neighbourhood walking, and Ross and Mirowsky (2001) reported that people in areas with more problems were more likely to walk, a finding they ascribed to poverty. However, the non-significant positive association between environmental neighbourhood problems and frequency of walking that we observed is not strong enough to support this argument.

In fact, we found no associations between perceptions of neighbourhood problems and walking, in line with many other studies (Yen et al., 2009; Foster et al., 2012; Foster and Giles-Corti, 2008; GilesCorti et al., 2013; Kerr et al., 2015; Fisher et al., 2004; Echeverría et al., 2008), although objective measures of neighbourhood design have been found to be important (Yen et al., 2009). This is supported by our finding regarding the importance of local services, which, although self-reported, may be considered more 'objective' than questions relating to perceptions of neighbourhood problems.

There may also be an issue of reverse causation: we recognise that our measure is of perceived environmental problems and that those with higher wellbeing scores may report environmental problems to be greater than those with poorer mental wellbeing. For example, those with higher wellbeing scores may be more concerned about the neighbourhood environment and therefore report problems to a greater extent, or those with lower wellbeing may perceive environmental incivilities to be less of a concern because they have adapted to adverse circumstances. An objective measure of environmental problems would be needed to explore this further. 
We found that social contact is important for the mental wellbeing and frequency of walking outdoors of older adults. Living alone is negatively associated with wellbeing, after controlling for social contact. With policy efforts increasingly directed towards "ageing in place" it will become more common for older people to live at home on their own, with fewer opportunities for social contact, especially as getting outdoors becomes restricted by their reduced physical mobility. Our results suggest that the positive associations of walking with mental wellbeing do not entirely counter the negative effects of living alone. It is therefore vital that policies promoting living at home longer simultaneously support and encourage walking as a pathway to mental wellbeing, and enable social contact as a means of promoting positive mental wellbeing, thereby reducing problems in older people arising from loneliness. It may be that these results are specific to the deprived urban context that we are studying. Nevertheless, this challenges assumptions that efforts to promote walking will necessarily lead to positive outcomes for all people in all places, and policy should take this nuance into account.

In contrast to finding no association with neighbourhood problems, those with more positive perceptions of local services such as street cleaning, public transport, street lighting and pavements have better mental wellbeing, but, counter to expectation, this is not explained by levels of neighbourhood walking. Positive perceptions of the quality of services provided might be associated with better wellbeing, due to same-source bias, given that the environmental and health reports are from the same individuals. However, Jones et al. (2014) suggest that associations between perceived neighbourhood and wellbeing are robust to same-source bias, and Elliott et al. (2014) found positive associations even after controlling for personality.

We expected the perceived quality of local amenities to be positively associated with levels of walking and wellbeing, but this was not true in either case. On the other hand, the use of local retail and non-retail amenities was positively associated with both walking and mental wellbeing. Walking in the local area therefore partially explains the higher wellbeing scores of those who use local amenities. Those not using local amenities may either not be using them at all or using them in locations beyond their neighbourhood. Given the nature of our sample (with only $22.4 \%$ of 
households owning a car), the former is most likely: older adults who may be confined to their home are less likely to be able to get out and use local amenities, with negative consequences for walking and wellbeing, although they may use destinations further away, which they access using other modes of transport. This is further supported by an examination of sources of walking in the sample, which suggests that most walking is functional, to run errands in the local neighbourhood. On this basis, the relationship between use of local amenities and walking is not surprising and nor is the finding that those who do not do such day-to-day activities report lower levels of wellbeing, as this is probably also indicative of restricted mobility, which itself has negative associations with wellbeing.

Frequency of walking partially mediates the relationship between feeling safe in the dark and positive mental wellbeing, but there is also an independent effect. This may be because the assessment of feeling safe walking after dark measures latent concepts of ontological security rather than purely feeling safe when outside, suggesting that positive perceptions of the environment can be beneficial to wellbeing even if that environment is not experienced directly.

Poorer physical health is associated with lower levels of mental wellbeing, which is further reduced through less frequent walking among those with poor physical health. This would suggest that encouraging even low levels of walking among those with physical health conditions has the potential to mediate some of their negative wellbeing consequences. Although age is positively associated with wellbeing, less frequent walking among the oldest age group has a negative effect on wellbeing, reinforcing the findings of other studies. However, other effects of ageing outweigh this negative effect in our model so that, overall, age is positively associated with mental wellbeing. This association between age and mental wellbeing, concurs with the findings of the Scottish Health Survey, wherein WEMWBS scores were highest for 65 to 74 year olds but decreased again after 75 (Scottish Government, 2015).

The positive association of car ownership with wellbeing might arise for three reasons. First, car ownership is often used as a proxy for income, and socioeconomic status is associated with higher levels of wellbeing (Jones et al., 2014). Second, giving up using a car in older age is often occurs in 
response to declines in functional and independent mobility (Musselwhite and Shergold, 2013), both of which negatively affect wellbeing. Third, the car provides mobility and access to destinations and other people, which is in itself important for wellbeing. Nordbakke and Schwanen's (2013) conceptualisation of the links between mobility and wellbeing show that physical activity is one of several components. Therefore, it seems, in this case, while walking itself is associated with wellbeing, other forms of mobility (e.g., car use) are also. For older adults living in deprived urban areas the ability to get out and about and to access destinations and social connections may be important for wellbeing, regardless of how that mobility is achieved. The wellbeing benefits associated with walking do partially explain why the built and social environments influence wellbeing, but relationships are not as strong as we might expect.

The negative associations of car ownership with walking are also expected, given that walking for transport is more common among those who do not own a car (Ogilvie et al., 2008). However, this means that car ownership has a complicated relationship with wellbeing. The overall effect in our model is positive but small. It appears that having a car is good for wellbeing, regardless of the negative effects on walking frequency (and thereby wellbeing). However, we suggest that this complex relationship requires more research in which the life course is considered. For individuals who have never owned a vehicle there may be stronger positive effects of walking on wellbeing in older age, although the long-term impacts of low income, a likely circumstance for our respondents, should not be ignored. However, if a lack of car ownership is related to declining functional mobility among adults who have always owned a car, the negative consequences for mental wellbeing of the loss of car ownership may be greater than any positive effects of more walking, especially as the ability to walk may also be limited at this point. This highlights the need to consider walking, mobility and mental wellbeing among older adults more holistically than is usually the case. Policies aimed at promoting health and wellbeing through transport should focus not only on the health benefits associated with active travel, but also about the importance of accessibility and mobility for wellbeing, by whichever mode that might be provided. In the longer term strategies aimed at reducing societal car dependence through urban planning andpromoting sustainable and inclusive mobility will 
be best placed to support well-being. However, in the short term policies aimed at travel behaviour change and active ageing should not perpetuate exclusion of those who already rely on active travel for their daily mobility in car-centric urban (and rural) areas.

The strength of the relationship between neighbourhood walking and mental wellbeing was not as strong as might be expected, possibly because walking activity was, by nature, utility-based rather than recreational. If walking is regarded as a necessity rather than as a leisure pursuit or a chosen activity then the relationship with wellbeing may not be positive. In a study by Christiansen et al. (2014) positive relationships between walkable neighbourhoods and walking persisted after controlling for self-selection and across life stages, but only for those with above-median incomes, suggesting that the importance of the environment for walking may be attenuated in lower income areas, as also suggested by Shortt et al. (2014) Ogilvie et al. (2008), and (Bostock, 2001) because walking is necessary, regardless of environmental conditions.

However, we do find associations between the built and social environment and frequency of walking. The relatively weak association between walking and wellbeing, coupled with the stronger direct associations between built and social environments with wellbeing and with walking, lend support to policy approaches which focus on improving the urban realm and providing safe, high quality urban environments. Such approaches should be adopted in contrast to those which focus on individuals behaviours and promote walking as a health behaviour, regardless of the environment in which it takes place. Such environments can support both walking and have direct associations with wellbeing, and may also enhance the experience of walking, in doing so strengthening relationships between walking and wellbeing similar to associations found in less deprived areas.

\subsection{Limitations}

Our survey was undertaken in the summer months and we must recognise the temporal variation in mobility of the older population. Poor weather is likely to lead to decreased mobility in the winter months (Hjorthol 2012). For those who have experienced a fall or who have a fear of falling, mobility could be severely restricted at particular times of year, highlighting the potential for seasonal variation 
in the relationships between the environment, mobility and mental wellbeing in an ageing population. We have assumed that the relationship between walking and wellbeing is linear, as is commonly the case in such studies. However, our results suggest that this may not be the case. For example, walking on 7 days of the week because it is the only form of transport available may not be pleasurable or, in that case, conducive to positive mental wellbeing as also suggested by Bostock (2001_ The role of the car in providing accessibility, mobility and wellbeing for older adults was not the focus here but is worthy of further research on the basis of these findings.

We recognise that our measure of walking does not cover all forms of independent neighbourhood mobility for older adults. For example, we do not know whether those using mobility scooters or wheelchairs would have interpreted their mobility as 'walking' and whether the wellbeing effects would be similar. Our measure of walking might be unsuitable for predicting differences in mental wellbeing. For example, Parker et al. (2008) found that objective measures of walking obtained from pedometers were better at predicting wellbeing than were self-reported measures.

For Lawton (1980), perceptions of the environment equate with quality of life and, in this sense, it is perhaps unsurprising that we find strong links between perceptions of the environment and mental wellbeing. Using objective measures of the built environment would help to disentangle the relationships of perceived and objective measures of the built environment with mental wellbeing.

\section{Conclusions}

Regeneration and policy initiatives that seek to improve the quality of the neighbourhood environment should be designed to increase walking (Longo et al., 2015), and to better mental wellbeing among older residents in deprived communities. However, our results suggest caution should be exercised in assuming that changes to the neighbourhood environment will lead to changes in walking frequency and subsequently wellbeing among ageing populations in deprived communities. While the neighbourhood environment has associations with wellbeing, these are not always explained by walking. 
Several aspects of our analysis indicate that there may be an element of necessary, utility walking for the people in our sample, which may limit the positive impacts of walking on wellbeing. Walking is already a frequent and widespread mode of transport in deprived areas, but if it is not a chosen activity and is undertaken in relatively unpleasant environments then it may not always be positive for wellbeing, even though we did find a small positive effect. This should temper our expectations of the possible health outcomes of efforts to increase levels of walking in deprived neighbourhoods. However, efforts to improve the urban realm, alongside facilitating accessibility and mobility for older adults, are likely to support the wellbeing of this population group and may also lead to an environment that is more supportive of walking that can be undertaken for pleasure rather than purely out of necessity. This is not to deny the importance of walking, but to recognise that relevance of the environment in which it takes place, if there are to be benefits for wellbeing.

Efforts need to be directed towards more appropriate environmental design as part of the regeneration process to ensure that the positive wellbeing effects of walking in pleasant environments are realised. Policy is increasingly concerned with designing the environment and encouraging active travel in order to improve wellbeing. In deprived urban environments, where walking is a necessary mode of transport, the role of the environment in relation to walking, and the importance of walking for wellbeing may be limited.

Although efforts to promote good urban design should be encouraged, in the context of ageing in place, the regeneration of deprived urban environments needs to take a more holistic approach to the design of the outdoor environments (Rosenberg and Everitt, 2001) to accommodate the needs of an ageing population. 


\section{References}

Bergland, A., Thorsen, K., Loland, N.W., 2010. The relationship between coping, self-esteem and health on outdoor walking ability among older adults in Norway. Ageing Soc. 30, 949-963. https://doi.org/10.1017/S0144686X1000022X

Bostock, L., 2001. Pathways of disadvantage? Walking as a mode of transport among low-income mothers. Heal. Soc. Care Community 9, 11-18.

Burton, E., 2015. Briefing: Mental well-being and the influence of place. Proc. ICE - Urban Des. Plan. 168, 161-163. https://doi.org/10.1680/udap.15.00024

Cahill, M., 2010. Transport, environment and society. Open University Press.

Carlson, J.A., Sallis, J.F., Conway, T.L., Saelens, B.E., Frank, L.D., Kerr, J., Cain, K.L., King, A.C., 2012. Interactions between psychosocial and built environment factors in explaining older adults' physical activity. Prev. Med. (Baltim). 54, 68-73. https://doi.org/10.1016/j.ypmed.2011.10.004

Cerin, E., Leslie, E., Sugiyama, T., Owen, N., 2009. Associations of multiple physical activity domains with mental well-being. Ment. Health Phys. Act. 2, 55-64. https://doi.org/10.1016/j.mhpa.2009.09.004

Christiansen, L.B., Madsen, T., Schipperijn, J., Ersbøll, A.K., Troelsen, J., 2014. Variations in active transport behavior among different neighborhoods and across adult life stages. J. Transp. Heal. https://doi.org/10.1016/j.jth.2014.10.002

Echeverría, S., Diez-Roux, A. V, Shea, S., Borrell, L.N., Jackson, S., 2008. Associations of neighborhood problems and neighborhood social cohesion with mental health and health behaviors: the Multi-Ethnic Study of Atherosclerosis. Health Place 14, 853-65. https://doi.org/10.1016/j.healthplace.2008.01.004

Elliott, J., Gale, C.R., Parsons, S., Kuh, D., 2014. Neighbourhood cohesion and mental wellbeing among older adults: a mixed methods approach. Soc. Sci. Med. 107, 44-51. https://doi.org/10.1016/j.socscimed.2014.02.027

Fisher, K.J., Li, F., Michael, Y., Cleveland, M., 2004. Neighborhood-level influences on physical activity among older adults: a multilevel analysis. J. Aging Phys. Act. 12, 45-63.

Foster, S., Giles-Corti, B., 2008. The built environment, neighborhood crime and constrained physical activity: an exploration of inconsistent findings. Prev. Med. (Baltim). 47, 241-51. https://doi.org/10.1016/j.ypmed.2008.03.017

Foster, S., Giles-Corti, B., Knuiman, M., 2012. Does Fear of Crime Discourage Walkers? A SocialEcological Exploration of Fear As a Deterrent to Walking. Environ. Behav. 46, 698-717. https://doi.org/10.1177/0013916512465176

Franke, T., Tong, C., Ashe, M.C., McKay, H., Sims-Gould, J., 2013. The secrets of highly active older adults. J. Aging Stud. 27, 398-409. https://doi.org/10.1016/j.jaging.2013.09.003

Gale, C.R., Dennison, E.M., Cooper, C., Sayer, A.A., 2011. Neighbourhood environment and positive mental health in older people: the Hertfordshire Cohort Study. Health Place 17, 867-74. https://doi.org/10.1016/j.healthplace.2011.05.003

Giles-Corti, B., Bull, F., Knuiman, M., McCormack, G., Van Niel, K., Timperio, A., Christian, H., Foster, S., Divitini, M., Middleton, N., Boruff, B., 2013. The influence of urban design on neighbourhood walking following residential relocation: longitudinal results from the RESIDE study. Soc. Sci. Med. 77, 20-30. https://doi.org/10.1016/j.socscimed.2012.10.016

Hjorthol, R., 2012. Winter weather - an obstacle to older people's activities? J. Transp. Geogr. null. https://doi.org/10.1016/j.jtrangeo.2012.09.003 
Hu, L., Bentler, P.M., 1999. Cutoff criteria for fit indexes in covariance structure analysis: Conventional criteria versus new alternatives. Struct. Equ. Model. A Multidiscip. J. 6, 1-55. https://doi.org/10.1080/10705519909540118

Jones, R., Heim, D., Hunter, S., Ellaway, A., 2014. The relative influence of neighbourhood incivilities, cognitive social capital, club membership and individual characteristics on positive mental health. Health Place 28, 187-93. https://doi.org/10.1016/j.healthplace.2014.04.006

Kerr, Z., Evenson, K.R., Moore, K., Block, R., Diez, A. V, 2015. Changes in walking associated with perceived neighborhood safety and police-recorded crime: The multi-ethnic study of atherosclerosis. Prev. Med. (Baltim). 73, 88-93. https://doi.org/10.1016/j.ypmed.2015.01.017

Koohsari, M.J., Badland, H., Giles-Corti, B., 2013. (Re)Designing the built environment to support physical activity: Bringing public health back into urban design and planning. Cities 35, 294 298. https://doi.org/10.1016/j.cities.2013.07.001

Lampinen, P., Heikkinen, R.-L., Kauppinen, M., Heikkinen, E., 2006. Activity as a predictor of mental well-being among older adults. Aging Ment. Health 10, 454-66. https://doi.org/10.1080/13607860600640962

Lawton, M.P., 1980. Environment and Aging. Brooks/Cole, Monterey, California.

Longo, A., George Hutchinson, W., Hunter, R., Tully, M.A., Kee, F., 2015. Demand response to improved walking infrastructure: A study into the economics of walking and health behaviour change. Soc. Sci. Med. https://doi.org/10.1016/j.socscimed.2015.08.033

Mason, P., Kearns, A., Livingston, M., 2013. "Safe Going": the influence of crime rates and perceived crime and safety on walking in deprived neighbourhoods. Soc. Sci. Med. 91, 15-24. https://doi.org/10.1016/j.socscimed.2013.04.011

McCormack, G.R., Shiell, A., Doyle-Baker, P.K., Friedenreich, C.M., Sandalack, B.A., 2014. Subpopulation differences in the association between neighborhood urban form and neighborhood-based physical activity. Health Place 28, 109-115. https://doi.org/10.1016/j.healthplace.2014.04.001

Musselwhite, C.B.A., Shergold, I., 2013. Examining the process of driving cessation in later life. Eur. J. Ageing 10, 89-100. https://doi.org/10.1007/s10433-012-0252-6

Nordbakke, S., Schwanen, T., 2013. Well-being and Mobility: A Theoretical Framework and Literature Review Focusing on Older People. Mobilities 9, 104-129. https://doi.org/10.1080/17450101.2013.784542

Ogilvie, D., Mitchell, R., Mutrie, N., Petticrew, M., Platt, S., 2008. Personal and environmental correlates of active travel and physical activity in a deprived urban population. Int. J. Behav. Nutr. Phys. Act. 5, 43. https://doi.org/10.1186/1479-5868-5-43

Parker, S.J., Strath, S.J., Swartz, A.M., 2008. Physical activity measurement in older adults: relationships with mental health. J. Aging Phys. Act. 16, 369-80.

Rao, M., Prasad, S., Adshead, F., Tissera, H., 2007. The built environment and health. Lancet 370, 1111-1113. https://doi.org/10.1016/S0140-6736(07)61260-4

Rosenberg, M., Everitt, J., 2001. Planning for aging populations: inside or outside the walls. Prog. Plann. 56, 119-168. https://doi.org/10.1016/S0305-9006(01)00014-9

Ross, C.E., Mirowsky, J., 2001. Neighborhood disadvantage, disorder, and health. J. Health Soc. Behav. 42, 258-76.

Rosseel, Y., 2012. lavaan : An R Package for Structural Equation Modeling. J. Stat. Softw. 48, 1-36. https://doi.org/10.18637/jss.v048.i02

Schwanen, T., Páez, A., 2010. The mobility of older people - an introduction. Spec. issue Mobil. 
older people 18, 591-595.

Scottish Government, 2015. Scottish Health Survey Topic Report: Mental Health and Wellbeing.

Shortt, N.K., Rind, E., Pearce, J., Mitchell, R., 2014. Integrating environmental justice and socioecological models of health to understand population-level physical activity. Environ. Plan. A 46, 1479-1495. https://doi.org/10.1068/a46113

Stafford, L., Baldwin, C., 2018. Planning Walkable Neighborhoods. J. Plan. Lit. 33, 17-30. https://doi.org/10.1177/0885412217704649

Stewart-Brown, S., Tennant, A., Tennant, R., Platt, S., Parkinson, J., Weich, S., 2009. Internal construct validity of the Warwick-Edinburgh Mental Well-being Scale (WEMWBS): a Rasch analysis using data from the Scottish Health Education Population Survey. Health Qual. Life Outcomes 7, 15. https://doi.org/10.1186/1477-7525-7-15

Sugiyama, T., Ward Thompson, C., 2007a. Outdoor environments, activity and the well-being of older people: conceptualising environmental support. Environ. Plan. A 39, 1943-1960.

Sugiyama, T., Ward Thompson, C., 2007b. Older people's health, outdoor activity and supportiveness of neighbourhood environments. Landsc. Urban Plan. 83, 168-175.

https://doi.org/10.1016/j.landurbplan.2007.04.002

Tennant, R., Hiller, L., Fishwick, R., Platt, S., Joseph, S., Weich, S., Parkinson, J., Secker, J., StewartBrown, S., 2007. The Warwick-Edinburgh Mental Well-being Scale (WEMWBS): development and UK validation. Health Qual. Life Outcomes 5, 63. https://doi.org/10.1186/1477-7525-5-63

Van Cauwenberg, J., De Bourdeaudhuij, I., De Meester, F., Van Dyck, D., Salmon, J., Clarys, P., Deforche, B., 2011. Relationship between the physical environment and physical activity in older adults: a systematic review. Heal. Place 17, 458-469.

Yen, I.H., Michael, Y.L., Perdue, L., 2009. Neighborhood environment in studies of health of older adults: a systematic review. Am. J. Prev. Med. 37, 455-63.

https://doi.org/10.1016/j.amepre.2009.06.022 
Table 1. Sample characteristics

\begin{tabular}{|c|c|c|c|c|c|}
\hline \multirow[b]{2}{*}{ Characteristic } & \multirow[b]{2}{*}{ Category } & \multirow[b]{2}{*}{$\begin{array}{l}\text { Percentage } \\
\text { in sample }\end{array}$} & \multicolumn{3}{|c|}{$\begin{array}{c}\text { Days walking in } \\
\text { neighbourhood in last } 7 \\
\text { days }\end{array}$} \\
\hline & & & Mean & SD & $\mathrm{p}$ \\
\hline \multicolumn{6}{|l|}{$\begin{array}{l}\text { Sociodemographic, personal and } \\
\text { residential: }\end{array}$} \\
\hline \multirow[t]{2}{*}{ Gender } & Male & 41.4 & 2.60 & 2.930 & \multirow{2}{*}{0.865} \\
\hline & Female & 58.6 & 2.57 & 2.869 & \\
\hline \multirow[t]{3}{*}{ Age group } & $60-69$ years & 46.8 & 2.98 & 2.938 & \multirow{3}{*}{$<0.001$} \\
\hline & 70-79 years & 39.0 & 2.45 & 2.882 & \\
\hline & $80+$ years & 14.2 & 1.66 & 2.518 & \\
\hline \multirow[t]{2}{*}{ Employment status } & $\begin{array}{l}\text { Retired/not } \\
\text { working }\end{array}$ & 95.3 & 2.53 & 2.877 & \multirow[t]{2}{*}{0.006} \\
\hline & Working & 4.7 & 3.65 & 3.035 & \\
\hline \multirow[t]{2}{*}{ Household type } & Living alone & 57.9 & 2.45 & 2.822 & \multirow[b]{2}{*}{0.072} \\
\hline & $\begin{array}{l}\text { Living with } 1+ \\
\text { person }\end{array}$ & 42.1 & 2.77 & 2.981 & \\
\hline \multirow[t]{2}{*}{ Education } & None/SLC/dk ${ }^{*}$ & 87.8 & 2.47 & 2.853 & \multirow{2}{*}{$<0.001$} \\
\hline & $>$ SLC & 12.2 & 3.41 & 3.048 & \\
\hline \multirow[t]{2}{*}{ Vehicle ownership/access } & $\mathrm{No} / \mathrm{dk}^{*}$ & 77.6 & 2.73 & 2.932 & \multirow{2}{*}{0.002} \\
\hline & Yes & 22.4 & 2.08 & 2.700 & \\
\hline \multirow[t]{3}{*}{ Built form of home } & House & 45.6 & 2.54 & 2.935 & \multirow{3}{*}{0.554} \\
\hline & $\begin{array}{l}\text { Low-rise flat or } \\
\text { tenement }\end{array}$ & 35.9 & 2.55 & 2.868 & \\
\hline & High-rise flat & 18.5 & 2.79 & 2.843 & \\
\hline \multirow{2}{*}{ Tenure } & Social-rented & 74.2 & 2.51 & 2.877 & \multirow{2}{*}{0.128} \\
\hline & Private sector & 25.8 & 2.81 & 2.931 & \\
\hline \multicolumn{6}{|l|}{ Long-term health conditions: } \\
\hline \multirow[t]{2}{*}{ Cardiovascular and respiratory } & No & 50.1 & 2.79 & 2.883 & \multirow{2}{*}{0.022} \\
\hline & Yes & 49.9 & 2.39 & 2.892 & \\
\hline \multirow{2}{*}{$\begin{array}{l}\text { Musculoskeletal and neurological affecting } \\
\text { movement }\end{array}$} & No & 93.6 & 2.63 & 2.913 & \multirow{2}{*}{0.064} \\
\hline & Yes & 6.4 & 1.97 & 2.524 & \\
\hline \multirow[t]{2}{*}{ Other physical conditions } & No & 77.6 & 2.69 & 2.905 & \multirow{2}{*}{0.035} \\
\hline & Yes & 22.4 & 2.25 & 2.830 & \\
\hline
\end{tabular}

"dk, don't know 
Table 2. Latent variables and their component manifest variables

\begin{tabular}{|c|c|c|}
\hline Latent variable & Measured variables & Fit indices \\
\hline $\begin{array}{l}\text { Neighbourhood environment } \\
\text { quality }\end{array}$ & $\begin{array}{l}4 \text { items: attractive buildings; } \\
\text { attractive environment; quiet } \\
\text { and peaceful environment; } \\
\text { parks and open spaces (1=very } \\
\text { poor; 5=very good) }\end{array}$ & $\mathrm{CFI}=1 ; \mathrm{RMSEA}=0$ \\
\hline $\begin{array}{l}\text { Neighbourhood problems } \\
\text { (incivilities) }\end{array}$ & $\begin{array}{l}9 \text { items: violence against the } \\
\text { person, including assaults and } \\
\text { muggings; people being } \\
\text { insulted, pestered or } \\
\text { intimidated in the street; people } \\
\text { being attacked or harassed } \\
\text { because of their skin colour or } \\
\text { ethnic origin; people using or } \\
\text { dealing drugs; people being } \\
\text { drunk or rowdy in public } \\
\text { places; gang activity; teenagers } \\
\text { hanging around on the street; } \\
\text { nuisance neighbours or } \\
\text { problem families; house break- } \\
\text { ins or burglaries (1=not a } \\
\text { problem; } 3=\text { serious problem) }\end{array}$ & $\begin{array}{l}\text { CFI=0.961; RMSEA }=0.08 \\
\text { [includes the following error } \\
\text { covariances: } \\
\square \text { Drugs and alcohol } \\
\square \text { Gangs and teen loitering } \\
\square \text { Alcohol and teen loitering } \\
\square \text { Alcohol and gangs } \\
\square \text { Drugs and teen loitering] }\end{array}$ \\
\hline $\begin{array}{l}\text { Neighbourhood problems } \\
\text { (environmental) }\end{array}$ & $\begin{array}{l}5 \text { items: vandalism, graffiti, } \\
\text { deliberate damage to property } \\
\text { or vehicles; rubbish or litter } \\
\text { lying around; vacant or derelict } \\
\text { buildings and sites; bad smells, } \\
\text { poor air quality; amount or } \\
\text { speed of traffic. ( } 1=\text { not a } \\
\text { problem; } 3=\text { serious problem) }\end{array}$ & $\mathrm{CFI}=0.981 ; \mathrm{RMSEA}=0.048$ \\
\hline Quality of local services & $\begin{array}{l}5 \text { items: policing; street } \\
\text { cleaning; public transport; } \\
\text { street lighting; paths and } \\
\text { pavements. (1=very poor; } \\
5=\text { very good) }\end{array}$ & $\mathrm{CFI}=0.961 ; \mathrm{RMSEA}=0.059$ \\
\hline Quality of local amenities & $\begin{array}{l}3 \text { items: availability of good } \\
\text { quality fruit and vegetables; } \\
\text { community and social venues; } \\
\text { shops. (1=very poor; } 5=\text { =ery } \\
\text { good) }\end{array}$ & $\mathrm{CFI}=1 ; \mathrm{RMSEA}=0$ \\
\hline Social contact & $\begin{array}{l}3 \text { items: frequency of meeting } \\
\text { relatives; meeting friends; } \\
\text { talking to neighbours ( } 1=\text { never; } \\
5=\text { =most days) }\end{array}$ & $\mathrm{CFI}=1 ; \mathrm{RMSEA}=0$ \\
\hline
\end{tabular}


Table 3. Estimates from the structural equation model

\begin{tabular}{|c|c|c|c|c|c|c|c|c|c|c|}
\hline \multirow[b]{2}{*}{ Variable } & \multicolumn{4}{|c|}{ Wellbeing } & \multicolumn{4}{|c|}{ Frequency of walking } & \multirow[b]{2}{*}{$\begin{array}{c}\text { Indirect } \\
\text { effects }\end{array}$} & \multirow[b]{2}{*}{$\begin{array}{l}\text { Total } \\
\text { effects }\end{array}$} \\
\hline & Estimate & SE & $\mathrm{p}$ & $\begin{array}{c}\text { Standardised } \\
\text { estimate }\end{array}$ & Estimate & SE & $\mathrm{p}$ & $\begin{array}{c}\text { Standardised } \\
\text { estimate }\end{array}$ & & \\
\hline Frequency of walking & 0.039 & 0.018 & 0.027 & 0.088 & - & - & - & - & & \\
\hline Social contact & 0.247 & 0.055 & 0.000 & 0.190 & 0.417 & 0.128 & 0.001 & 0.141 & 0.016 & 0.263 \\
\hline Neighbourhood quality & 0.154 & 0.043 & 0.000 & 0.198 & 0.251 & 0.113 & 0.026 & 0.141 & 0.010 & 0.164 \\
\hline Neighbourhood problems (incivilities) & -0.175 & 0.065 & 0.007 & -0.132 & 0.181 & 0.177 & 0.304 & 0.060 & 0.007 & -0.168 \\
\hline Neighbourhood problems (environmental) & 0.267 & 0.107 & 0.012 & 0.216 & 0.240 & 0.265 & 0.365 & 0.085 & 0.009 & 0.276 \\
\hline Quality of local services & 0.167 & 0.070 & 0.017 & 0.153 & -0.145 & 0.173 & 0.404 & -0.058 & -0.006 & 0.161 \\
\hline Quality of local amenities & 0.055 & 0.041 & 0.180 & 0.063 & -0.031 & 0.102 & 0.761 & -0.015 & -0.001 & 0.054 \\
\hline Use of local retail amenities & 0.093 & 0.042 & 0.026 & 0.074 & 0.994 & 0.101 & 0.000 & 0.344 & 0.039 & 0.132 \\
\hline Use of local non-retail amenities & 0.117 & 0.038 & 0.002 & 0.097 & 0.410 & 0.085 & 0.000 & 0.149 & 0.016 & 0.133 \\
\hline Feel safe walking alone locally after dark & 0.054 & 0.011 & 0.000 & 0.171 & 0.065 & 0.023 & 0.005 & 0.090 & 0.003 & 0.057 \\
\hline Living alone & -0.068 & 0.033 & 0.037 & -0.067 & -0.099 & 0.076 & 0.193 & -0.042 & -0.004 & -0.072 \\
\hline Access to vehicle & 0.084 & 0.040 & 0.034 & 0.070 & -0.474 & 0.089 & 0.000 & -0.171 & -0.018 & 0.066 \\
\hline Cardiorespiratory health condition & -0.192 & 0.033 & 0.000 & -0.190 & -0.178 & 0.072 & 0.013 & -0.077 & -0.007 & -0.199 \\
\hline Musculoskeletal health condition & 0.037 & 0.059 & 0.530 & 0.018 & -0.215 & 0.164 & 0.190 & -0.046 & -0.008 & 0.029 \\
\hline Other physical health condition & -0.164 & 0.037 & 0.000 & -0.135 & -0.210 & 0.089 & 0.018 & -0.076 & -0.008 & -0.172 \\
\hline Age (70-79 years) & 0.129 & 0.034 & 0.000 & 0.125 & -0.147 & 0.078 & 0.059 & -0.062 & -0.006 & 0.123 \\
\hline Age ( $80+$ years $)$ & 0.132 & 0.048 & 0.006 & 0.091 & -0.354 & 0.121 & 0.003 & -0.107 & -0.014 & 0.118 \\
\hline Sex (female vs. male) & 0.139 & 0.032 & 0.000 & 0.135 & 0.072 & 0.074 & 0.329 & 0.031 & 0.003 & 0.142 \\
\hline Employed & 0.110 & 0.078 & 0.155 & 0.046 & 0.237 & 0.178 & 0.182 & 0.044 & 0.009 & 0.119 \\
\hline Educational qualifications & 0.121 & 0.049 & 0.015 & 0.078 & 0.301 & 0.108 & 0.005 & 0.085 & 0.012 & 0.133 \\
\hline
\end{tabular}




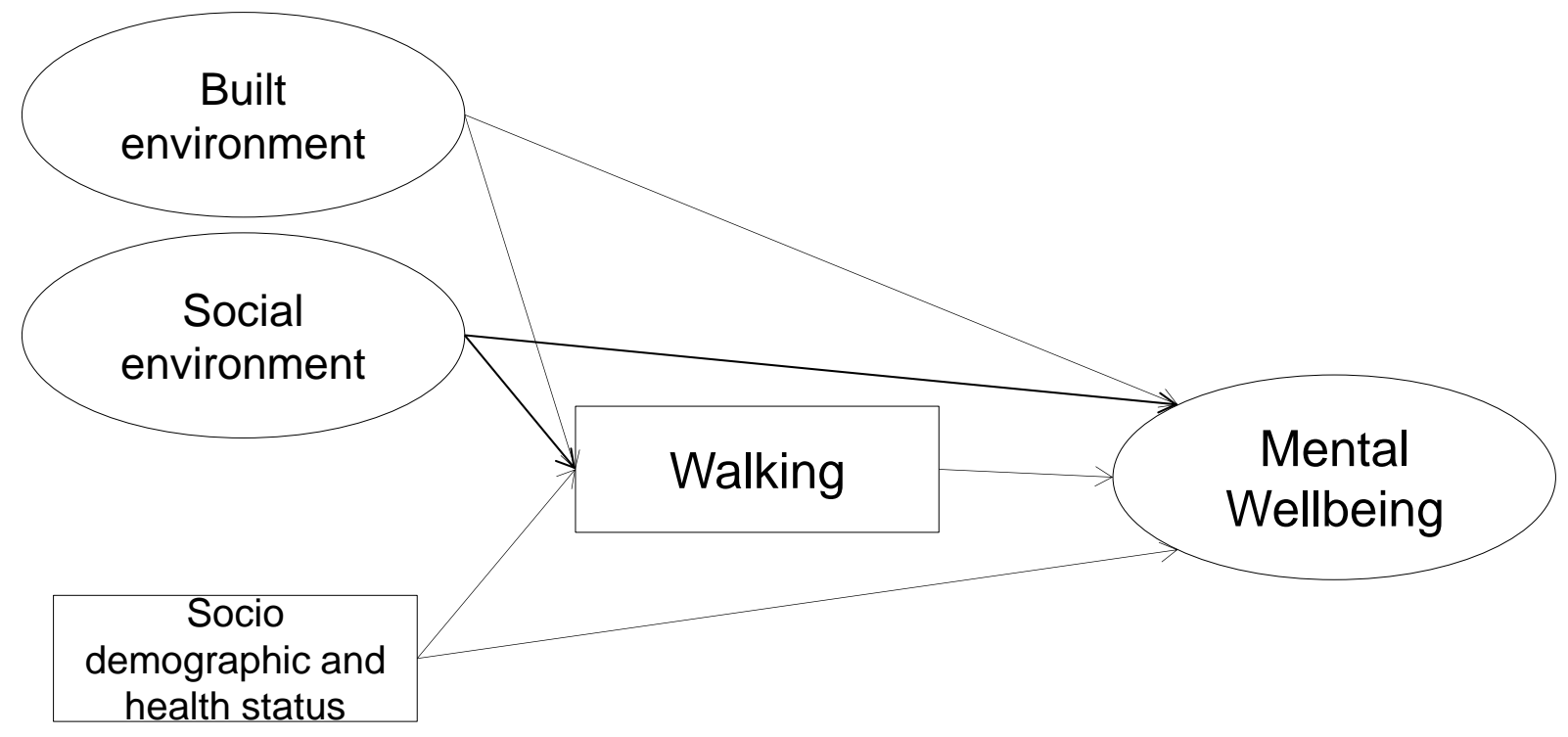

Figure 1. Conceptual model of relationship between environmental perception, walking and mental wellbeing. 


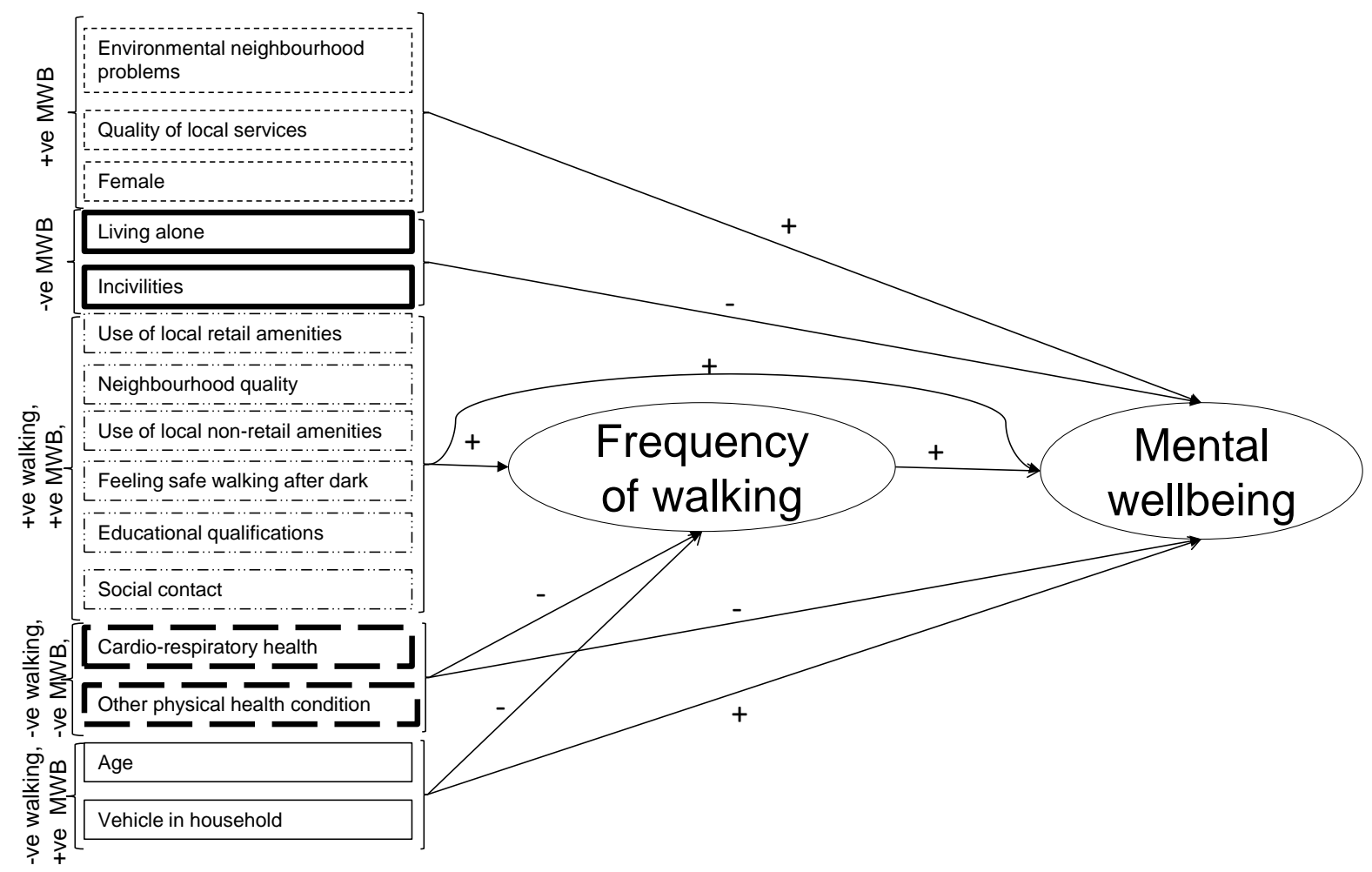

Figure 2. Significant relationships grouped by the relationships exogenous variables have on endogenous variables in the model (e.g the first three variables have a positive relationship with wellbeing and no relationship with walking). 